\title{
Impact of Oral and Dental Health on Children's and Parents' Quality of Life Based on Early Childhood Oral Health Impact Scale (ECOHIS) Index
}

\author{
Fatemeh Sadat Sajadi ${ }^{1, *}$, Lida Pishbin ${ }^{1}$, Seyed Hadi Azhari ${ }^{2}$, Mahmood Moosazadeh ${ }^{3}$ \\ ${ }^{1}$ Department of Pediatric Dentistry, School of Dentistry, Kerman University of Medical Sciences, Kerman, Iran \\ ${ }^{2}$ Private Practice, Mazandaran, Iran \\ ${ }^{3}$ Health Sciences Research Center, Faculty of Health, Mazandaran University of Medical Sciences, Sari, Iran \\ *Corresponding author: fsajadi1234@gmail.com
}

Received January 22, 2015; Revised February 20, 2015; Accepted February 25, 2015

\begin{abstract}
Background: Oral and dental health-related quality of life means the physical and psychological satisfaction with oral health status and the appearance of the teeth. The aim of this study was to assess the impact of oral and dental health on children's and parent's quality of life based on Early Childhood Oral Health Impact Scale (ECOHIS) index. Materials and Methods: In this cross-sectional study 400 children (2-5 years of age) were selected from the Pediatric Department of Kerman Dental School. A clinical oral examination was performed and their dmft was documented. Then the parents completed the ECOHIS questionnaire. Data were analyzed by chisquared test, two-sample t-test and Mann-Whitney test. Results: The mean of dmft in children was 5.6 \pm 3.6 . The mean scores obtained from ECOHIS questionnaire in the child and parent impact section were $4.07 \pm 0.79$ and $3.28 \pm 0.83$, respectively. There was an inverse statistical relationship between the mean of dmft and quality of life in children and parents $(\mathrm{P}<0.05)$. Conclusion: Children's oral and dental health has a significant impact on children's and parents' quality of life. This impact on children's quality of life is more than that on parents.
\end{abstract}

Keywords: ECOHIS index, pre-school children, quality of life, oral and dental health, dmft index

Cite This Article: Fatemeh Sadat Sajadi, Lida Pishbin, Seyed Hadi Azhari, and Mahmood Moosazadeh, "Impact of Oral and Dental Health on Children's and Parents' Quality of Life Based on Early Childhood Oral Health Impact Scale (ECOHIS) Index.” International Journal of Dental Sciences and Research, vol. 3, no. 2 (2015): 28-31. doi: 10.12691/ijdsr-3-2-2.

\section{Introduction}

Health-related quality of life means individual satisfaction with one's body and psychological characteristics based on which the individual achieves the ability to carry out his/her routine activities. [1] Oral health which is part of the individual's body health includes the health of the oral cavity and the relevant tissues' health that provides the individual with the ability to eat, talk and establish suitable social relations. Oral condition is an effective factor in oral health-related quality of life. [2] Also, the assessment of the oral health impact on children's quality of life is very important because oral status can affect children's growth, selfconfidence, socialization and learning abilities [3].

Using a standard index can be very useful to identify the effects that oral problems can have on children's quality of life. Numerous methods have been introduced to evaluate the effect of oral health status on individuals' quality of life; some of these have been provided for schoolchildren $[4,5]$.

These methods usually are in the form of interviews with schoolchildren who are able to talk and write or in the form of questionnaires that are completed by the children or their parents. $[6,7,8]$ However, the assessment of preschool children's oral health condition and its impact on quality of life needs special methods. Preschool children cannot read, write and express their attitudes, feelings and emotions $[9,10]$.

One of the indices designed to evaluate the oral healthrelated quality of life in preschool children is Early Childhood Oral Health Impact Scale (ECOHIS), which is a successful questionnaire in this field [2].

This questionnaire was first designed in the UK and USA to assess the impact of oral health problems on quality of life in preschool children and their families.[2] Then it was translated into Brazilian, French and Chinese in order to be used in other countries. $[11,12,13]$ In Iran, this questionnaire was translated into Farsi by Jabarifard et al and its validity and reliability have been verified [14].

In addition, Saleki et al in 2011 evaluated the sensitivity and responsiveness of ECOHIS questionnaire to routine dental treatments in Isfahan. They concluded that this questionnaire is properly sensitive and responsive. [15] Pani et al in 2012 performed a study entitled 'Differences in perceptions of early childhood oral health-related quality of life between parents in Saudi Arabia'. The results of this study indicated that fathers had significantly 
less awareness about the impact of children's oral health on their life quality compared with mothers [16].

Since life quality has a direct role in children's learning, activities and socialization it is necessary to assess oral health impact on children's quality of life is necessary. Furthermore, since there are different cultures and traditions in different societies the parents may have different attitudes and awareness about the impact of oral health-related quality of life on their children. Therefore the evaluation of this index might yield distinct results in different societies.

The aim of this study was to evaluate the impact of oral and dental health on children's and parents' quality of life based on Early Childhood Oral Health Impact Scale (ECOHIS) index.

\section{Materials and Methods}

In this cross-sectional, descriptive-analytical study, 400 parents of 2-5-year-old children referring to the Pediatric Department of Kerman Dental School were selected sequentially. The inclusion criteria consisted of parents with 2-5-year-old children from both sexes, without any systemic diseases and no long-term use of drugs. The exclusion criteria consisted of children with any debilitating systemic diseases or congenital syndromes.

Furthermore, the children older or younger than the 2-5-year age group were excluded from the study. The present study was approved by the Ethics Committee of Kerman University of Medical Sciences (K/92/378). After obtaining informed consent from the parents, the questionnaire was hand in.

The ECOHIS questionnaire has two parts. The first part includes demographic information (sex, age, the parent who completed the questionnaire, i.e. the father or mother, parents' level of education).

The second part includes 13 questions in two fields. One field is related to the impact of oral health on the child's life quality with 9 questions that comprises of four subscales: child symptom (1 item), child function (4 items), child psychology (2 items) and child selfimage/social interaction (2 items). The second field is related to the impact of oral health on family's life quality with 4 questions that contains two subscales: parental distress (2 items) and family function (2 items). The questions are scored based on Likert scale: Never (score 0 ); Hardly ever (score 1); Occasionally (score 2); Often (score 3); Very often (score 4); Don’t know (score 5). Item scores are simply added to create a total scale score. Generally the total scores of this index have range of 0-52, that the scores range $0-36$ are for child impact section and 0-16 for child impact section. Higher scores indicating grater impacts and/or more problems in children's oral and dental health. [11] Also there were 2 questions at the end of the questionnaire about parental satisfaction (very low to very high) and evaluation (very bad to very good) of their children's oral and dental status.

In addition, to evaluate the relation between children's oral and dental health and their quality of life and that of parents, the child's oral cavity and teeth were examined on a dental unit with an explorer and a mirror. The dmft index (decayed teeth, missing teeth, and filled teeth) of the children was registered according to WHO caries diagnostic criteria to determine the decayed, missing, filled teeth. The acquired numbers are simply added to create a total score for any child. Mean and SD were used to describe continuous variables.

Then, the child's oral and dental status was discussed with their parents and correct principles of oral hygiene were instructed.

After collecting the questionnaires, the data were analyzed by chi-squared test, two-sample t-test and MannWhitney test. $\mathrm{P}$ value of less than 0.05 was considered to be significant.

\section{Results}

The results indicated that of 400 children participating in the study, $54 \%$ were male and $46 \%$ were female. Of those completing the questionnaires $72.2 \%$ were mothers and $23.8 \%$ were fathers. The majority of fathers (44\%) and mothers (57.2\%) were high school and college graduates.

The mean of dmft in children was 5.6 \pm 3.6 . The linear regression test indicated an inverse relationship between the mean of dmft and children's and parents' life quality $(\mathrm{P}<0.001)$.

The mean and standard deviation of the scores achieved in the field of the impact of oral and dental health on child's quality of life was $4.07 \pm 0.79$, while the mean and standard deviation of the scores in the field of parents' quality of life was $3.28 \pm 0.83$ (Table 1 and Table 2).

Table 1. Distribution of parent ECOHIS responses in field of oral and dental health impact in child's quality of life

\begin{tabular}{|c|c|c|c|c|c|c|}
\hline Child impacts & Never N (\%) & Hardly ever N (\%) & Occasionally N (\%) & Often N (\%) & Very often N (\%) & Don't know N(\%) \\
\hline Oral/dental pain & $25(6.2)$ & $70(17.5)$ & $120(30)$ & $75(18.8)$ & $106(26.5)$ & $4(1)$ \\
\hline Difficulty drinking & $20(5)$ & $37(9.2)$ & $70(17.5)$ & $104(26)$ & $147(36.8)$ & $22(5.5)$ \\
\hline Difficulty eating & $26(6.5)$ & $68(17)$ & $68(17)$ & $92(23)$ & $122(30.5)$ & $24(6)$ \\
\hline Difficulty pronouncing words & $18(4.5)$ & $10(2.5)$ & $12(3)$ & $54(13.5)$ & $273(68.2)$ & $33(8.2)$ \\
\hline Missed preschool or school & $7(1.8)$ & $19(4.8)$ & $41(10.2)$ & $34(8.5)$ & $281(70.2)$ & $18(4.5)$ \\
\hline Trouble sleeping & $28(7)$ & $37(9.2)$ & $67(16.8)$ & $88(22)$ & $173(43.2)$ & $7(1.8)$ \\
\hline Irritable or frustrated & $19(4.8)$ & $74(18.5)$ & $71(17.8)$ & $95(23.8)$ & $131(32.8)$ & $10(2.5)$ \\
\hline Avoided smiling or laughing & $9(2.2)$ & $23(5.8)$ & $20(5)$ & $85(21.2)$ & $241(60.2)$ & $22(5.5)$ \\
\hline Avoided talking & $12(3)$ & $16(4)$ & $14(3.5)$ & $77(19.2)$ & $257(64.2)$ & $24(6)$ \\
\hline
\end{tabular}

Table 2. Distribution of parent ECOHIS responses in field of oral and dental health impact in family's quality of life

\begin{tabular}{|c|c|c|c|c|c|}
\hline Question & Very low N (\%) & Low N (\%) & High N (\%) & Very high N (\%) & Don't know N (\%) \\
\hline Satisfaction from child's oral and dental appearance & $107(26.8)$ & $140(35)$ & $80(20)$ & $43(10.8)$ & $30(7.5)$ \\
\hline Question & Very bad N (\%) & Bad N (\%) & Good N (\%) & Very good N (\%) & Don't know N (\%) \\
\hline Evaluation of child's oral and dental status & $60(15)$ & $124(31)$ & $131(32.8)$ & $75(18.7)$ & $10(2.5)$ \\
\hline
\end{tabular}


In addition, the results indicated that the oral and dental health impact on children's quality of life had an inverse relation with age. It means that with an increase in age the children's quality of life decreased.

Also parent's satisfaction from child's oral and dental appearance was low in most of parents (35\%) and $32.8 \%$ of parents reported that their child's oral and dental status is good (Table 3).
Children's quality of life did not have a significant relationship with father's level of education $(\mathrm{P}=0.7)$, while, children's quality of life had a significant relationship with mother's level of education $(\mathrm{P}=0.006)$. Children's quality of life did not exhibit a significant relationship with sex $(\mathrm{P}=0.59)$.

Table 3. Distribution of parent ECOHIS responses about satisfaction and evaluation of children's oral and dental status

\begin{tabular}{|c|c|c|c|c|c|c|}
\hline Family impacts & Never N (\%) & Hardly ever N (\%) & Occasionally N (\%) & Often N (\%) & Very often N (\%) & Don’t know N(\%) \\
\hline Been upset & $61(15.2)$ & $92(23)$ & $75(18.8)$ & $74(18.5)$ & $91(22.8)$ & $7(1.8)$ \\
\hline Felt guilty & $36(9)$ & $58(14.5)$ & $38(9.5)$ & $94(23.5)$ & 147(36.8) & $27(6.8)$ \\
\hline Time off from work and home & $25(6.2)$ & 93(23.3) & $108(27)$ & 154(38.5) & 397(99.2) & $23(5.7)$ \\
\hline Financial impact & $36(9)$ & $66(16.5)$ & $60(15)$ & $82(20.5)$ & 142(35.5) & $14(3.5)$ \\
\hline
\end{tabular}

\section{Discussion}

The results of this study indicated a significant inverse relationship between the mean of child's dmft and their and their parents' quality of life. In addition, the impact of oral and dental health on child's quality of life was more than that on parents'. There was a significant relationship between the children's quality of life and age and mother's level of education. However, there was no significant relationship between children's quality of life and sex and father's level of education.

It is possible that children under the age of 5 have many oral health problems such as dental pains, early childhood caries (ECC) and dental traumas. Nevertheless, the effect of oral disease and health on social and mental activities of children and their families has not been completely evaluated. To this end, tools are required to evaluate the oral health-related quality of life. [12] In this study, the questionnaire of the Early Childhood Oral Health Impact Scale (ECOHIS) was used, which was translated into Farsi and validated by Jabarifar et al in 2010 [14].

The mean of scores achieved from ECOHIS questionnaire in the field of the impact of oral and dental health on child's quality of life was $4.07 \pm 0.79$, while this was $2.6 \pm 3.3$ in a study by Scarpelli et al. Furthermore, the mean of scores in the family's impact in this study was $3.2 \pm 0.83$, while it was $1.4 \pm 2.2$ in Scarpelli's study [13].

In this study, the impact of oral health in two fields of child and family's life was significantly more than that in a study conducted in Brazil. [13] Furthermore, the mean of ECOHIS scores in a study by Pani et al in Saudi Arabia was $5.5 \pm 9.4$, which is more than that the present study. [16] The mean of dmft in this study was $5.6 \pm 3.6$, while in a study in Brazil it was $2.1 \pm 3.1$, with $54 \%$ of children in that study having a dmft value of zero. [13] In addition, in the study by Pani et al the mean of dmft was $2.7 \pm 4$. [16] The results indicated that in this study, compared with the two studies mentioned above, the children's oral and dental health status was poorer.

The results indicated that the impact of children's oral and dental problems on child's quality of life was more than that on parents'; the mean of children's score was 4.07 versus 3.2 in parents, consistent with studies carried out by Li and Scarpelli. [12,13] The impact of children's oral and dental health on their quality of life can be revealed by the effects on child's growth, weight, socialization, self-confidence and even learning abilities $[14,17]$.
In this study, the impact of oral and dental health on children's quality of life exhibited a significant relationship with age, i.e. an increase in age resulted in a decrease in quality of life, consistent with the results of a study by Li et al, in which the quality of life exhibited a significant relationship with age, i.e. an increase in age increased the impact of oral health on quality of life [12].

In fact, the reason is children's inability to report their pain and discomfort when eating. Furthermore, lower social and cognitive growth of younger children makes them less susceptible to the influence of social factors such as not speaking or smiling.

In this study, the impact of oral and dental health on quality of life did not exhibit a significant relationship with sex, consistent with the results reported by Younesian et al [18].

Usually, male and female preschool children do not have a difference in nutrition, hormonal changes, oral hygiene and parental care. However, with aging this difference might be significant in both sexes.

It must be pointed out that responding to ECOHIS questionnaire is completely dependent on parents' understanding of their children's health and disease. Parents may have different attitudes toward their children's health compared with other parents and even their child. [14] Therefore, in addition to social factors, level of education can exert different effects on study results in such a way that in this study, mothers' level of education had a significant effect on children's oral health-related quality of life compared to fathers' level of education, which might be attributed to the minor role of father in children's oral health care in our society.

One of the important challenges when evaluating children's oral and dental health problems is children's lack of cognitive growth and unreliable responses. Therefore, it is required that parents help assess children's quality of life. [19] Therefore, parents' individual and social differences and their accuracy and responses to the questions might affect the study results.

One of the limitations of this study was unequal distribution of children's age groups. However, by considering the fact that parents were included in the study, whose children were at the age range of 2-5 years old, the unequal distribution of children's age was unpredictable. By considering the large sample size in this study, it does not seem that unequal distribution of age disrupts the study validity. Such a limitation exists $n$ similar studies that had smaller sample sizes compared to this study $[11,14]$. 


\section{Conclusion}

The results of this study indicated a significant inverse relationship between the mean of dmft of children and their and their parents' quality of life. In addition, the results indicated that the impact of oral and dental health on children's quality of life is more than that on their parents'. Furthermore, the impact of oral and dental health on children's quality of life had a significant relationship with children's age and mother's level of education. However, this factor did not exhibit a significant relationship with children's sex and father's level of education.

It is suggested that a study be performed in the society by using ECOHIS questionnaire in the form of an epidemiologic study in order to compare its results with the results of the present study.

\section{Acknowledgments}

This paper was based on a thesis submitted to the School of Dentistry, Kerman University of Medical Sciences. Financial support of this study provided by the Vice Chancellor for Research, Kerman University of Medical Sciences is warmly acknowledged. Also we thanks from all participating parents and students.

\section{References}

[1] Khadem P, Jabari far E, Maroofi V, Ghasemi D, Mohammad taher V, "The Relationship between Oral and dental health and quality of life based on DIDL index” J Res Dent Sci., 7, 41-35, 2011.

[2] Gift HC, Reisine ST, Larach DC, "The social impact of dental problems and visits”. Am J Public Health., 82, 1663-8, 1992.

[3] Petersen PE, “The World Oral Health Report 2003: Continuous improvement of oral health in the 21st century-the approach of the WHO Global Oral Health Program.” Community Dent Oral Epidemiol., 31, 3-23, 2003.

[4] Yusuf H, Gherunpong S, Sheiham A, Tsakos G, "Validation of an English version of the Child-OIDP index, an oral health-related quality of life measure for children. Health and Quality of Life Outcomes 2006; 4: 38-44.

[5] Easton JA, Landgraf JM, Casamassimo PS, Wilson S, Ganzberg S. Evaluation of a generic quality of life instrument for early childhood caries-related pain. Community Dent Oral Epidemiol 2008; 36: 434-40.

[6] Foster Page LA, Thomson WM, Jokovic A, Locker D. Epidemiological evaluation of short-form versions of the Child Perception Questionnaire. Eur J Oral Sci 2008; 116: 538-44.

[7] Locker D, Jokovic A, Stephens M, Kenny D, Tompson B, Guyatt G. Family impact of child oral and oro-facial conditions. Community Dent Oral Epidemiol 2002; 30: 438-48.

[8] Allen PF, McMillan AS, Locker D. An assessment of sensitivity to change of the Oral Health Impact Profile in a clinical trial. Community Dent Oral Epidemiol 2001; 29: 175-82.

[9] Filstrup SL, Briskie D, da FM, Lawrence L, Wandera A, Inglehart MR. Early childhood caries and quality of life: child and parent perspectives” Pediatr Dent., 25, 431-40, 2003.

[10] Rebok G, Riley A, Forrest C, Starfield B, Green B, Robertson J, et al, "Elementary school-aged children's reports of their health: a cognitive interviewing study” Qual Life Res., 10, 59-70, 2001.

[11] Lee GH, McGrath C, Yiu CK, King NM, "Translation and validation of a Chinese language version of the Early Childhood Oral Health Impact Scale (ECOHIS)” Int J Paediatr Dent., 19, 399-405, 2009.

[12] Li SH, Veronneau J, Allison PJ, "Validation of a French language version of the Early Childhood Oral Health Impact Scale (ECOHIS)" Health and Quality of Life Outcomes 6, 9-15, 2008.

[13] Scarpelli AC, Oliveira BH, Tesch FC, Leao AT, Pordeus IA, Paiva SM, "Psychometric properties of the Brazilian version of the Early Childhood Oral Health Impact Scale (B-ECOHIS)” BMC Oral Health 11, 19-29, 2011.

[14] Jabarifar SE, Golkari A, IJadi MH, Jafarzadeh M, Khadem P, "Validation of a Farsi version of the Early Childhood Oral Health Impact Scale (F-ECOHIS)” BMC Oral Health., 10, 4, 2010.

[15] Saleki M, Jabarifar E, Soheilipour SH, Hajizadeh F, “ Assessing the sensitivity and responsiveness of Early Childhood Oral Health Impact Scale to routine dental treatments on life quality of preschool children in Isfahan in 2011 "Journal of Isfahan Dental School., 7, 688-97, 2012.

[16] Pani SH, Badea L, Mirza S, Elbaage N, "Differences in perceptions of early childhood oral health-related quality of life between fathers and mothers in Saudi Arabia" International Journal of Paediatric Dentistry., 22, 244-9, 2012.

[17] Martins-Júnior P, Ramos-Jorge J, Paiva P, Marques L, RamosJorge M, "Validations of the Brazilian version of the Early Childhood Oral Health Impact Scale (ECOHIS)” Cad. Saúde Pública Rio de Janeiro., 28, 367-74, 2012.

[18] Kavand G, Younesian F, Saffar Shahroudi A, Dorri M, Akbarzadeh Baghban A, Khoshnevisan M, "Oral Health Related Quality of Life among Iranian children: Part I-Validity, reliability, prevalence and severity assessment of daily impact factors" J Dent Sch., 27, 187-196, 2010.

[19] Eiser C, Morse R, “Can parents rate their child's health-related quality of life? Results of a systematic review” Qual Life Res., 10, 347-57, 2001. 